\begin{tabular}{|c|c|c|}
\hline$r$ & \multicolumn{2}{|c|}{ Case Rep Gastroenterol 2013;7:169-174 } \\
\hline logy & $\begin{array}{l}\text { DOI: } 10.1159 / 000350558 \\
\text { Published online: March 22, } 2013\end{array}$ & $\begin{array}{l}\text { (C) } 2013 \text { S. Karger AG, Basel } \\
\text { 1662-0631/13/0071-0169 } \$ 38.00 / 0 \\
\text { www.karger.com/crg }\end{array}$ \\
\hline & \multicolumn{2}{|c|}{$\begin{array}{l}\text { This is an Open Access article licensed under the terms of the Creative Commons Attribution } \\
\text { NonCommercial-NoDerivs } 3.0 \text { License (www.karger.com/OA-license), applicable to the } \\
\text { online version of the article only. Distribution for non-commercial purposes only. }\end{array}$} \\
\hline
\end{tabular}

\title{
Hepatocellular Carcinoma with Sarcomatoid Change without Anticancer Therapies
}

\author{
Naoki Yoshida ${ }^{a}$ Yutaka Midorikawa ${ }^{a}$ Takahiro Kajiwara ${ }^{a}$ Nao Yoshida ${ }^{a}$ \\ Hisashi Nakayama $^{a}$ Masahiko Sugitani $^{b}$ Tadatoshi Takayama $^{a}$ \\ Departments of ${ }^{a}$ Digestive Surgery and ${ }^{b}$ Pathology, Nihon University School of Medicine, \\ Tokyo, Japan
}

\section{Key Words}

Sarcomatoid hepatocellular carcinoma · Transcatheter arterial chemoembolization .

Radiofrequency ablation · Immunohistochemistry

\begin{abstract}
Hepatocellular carcinoma ( $\mathrm{HCC}$ ) with sarcomatoid change is a rare neoplasm of the liver, and recurrent therapies for HCC such as transcatheter arterial chemoembolization and percutaneous ablation therapy are presumed to promote sarcomatoid change. A 73-year-old man was admitted to our hospital diagnosed as having liver cancer originating from hepatitis Crelated cirrhosis without any previous treatment for HCC. Ultrasonography showed that the tumor was hypoechoic, $3 \mathrm{~cm}$ in diameter, with unclear margins. Computed tomography demonstrated a low-density lesion with ring enhancement on delayed phase. Under a diagnosis of poorly differentiated HCC the patient underwent liver resection. Histologically, the tumor consisted of proliferation of spindle-shaped sarcomatoid carcinoma cells with unclear trabecular and pseudoglandular structures including a nodule of typical moderately differentiated HCC, which was observed to shift mutually in one region. Here, we report a case of sarcomatoid HCC with a review of the literature.
\end{abstract}

\section{Introduction}

Sarcomatoid carcinoma is a relatively rare malignant tumor, which can be observed in diverse organs, including the lung, breast, bladder, prostate, skin and liver, and which has been called spindle cell carcinoma, pseudosarcoma or carcinosarcoma [1, 2]. Its malignant cells harbor histological, cytological or molecular features of both epithelial and mesenchy-

Yutaka Midorikawa, MD

Department of Digestive Surgery, Nihon University School of Medicine

30-1 Oyaguchi Kami-machi, Itabashi-ku, Tokyo 173-8610 (Japan)

E-Mail mido-tky@umin.ac.jp 
mal tumors. The prognosis of this rare form of cancer is quite unfavorable because of rapid growth, frequent metastasis, low resectability rate and high incidence of recurrence even after curative resection [1,2], and its survival rates have not been well documented to date.

Clinically, sarcomatoid hepatocellular carcinoma (HCC) is generally caused by necrosis and degeneration due to repeated non-surgical therapy such as transcatheter arterial chemoembolization, radiofrequency ablation and percutaneous ethanol injection [3-5]. The incidence of HCC with sarcomatoid change has increased markedly in recent years; it is now found in about $1.8-2.0 \%$ of surgical cases and $3.9-9.4 \%$ of autopsy cases $[2,4]$. On the other hand, sarcomatoid HCC without previous therapies is extremely rare; the precise pathogenesis of sarcomatoid transformation of liver tumors is still unclear, and there are only a few reports of such cases [6].

We describe herein a patient with sarcomatoid HCC without any previous therapies in whom preoperative diagnosis was difficult, and pay special attention to the incidence, pathogenesis, prognosis and differential diagnosis of sarcomatoid HCC.

\section{Case Report}

A 73-year-old man was admitted to our hospital diagnosed as having liver cancer originating from hepatitis C-related cirrhosis. Laboratory tests showed elevated serum carcinoembryonic antigen $(6.5 \mathrm{ng} / \mathrm{ml}$; normal $<5.0 \mathrm{U} / \mathrm{l})$, carbohydrate antigen $19-9(42.5 \mathrm{U} / \mathrm{ml}$; normal $<37.0 \mathrm{U} / \mathrm{ml})$ and serum alpha-fetoprotein $(12.5 \mathrm{ng} / \mathrm{ml}$; normal $<10 \mathrm{ng} / \mathrm{ml})$ levels, while liver function values and des-r-carboxyprothrombin were within the normal range. Imaging modalities showed two liver tumors, one of which was located in segment 7 of the liver and was diagnosed as typical HCC. On the other hand, ultrasonography showed that the tumor in segment 6 was a hypoechoic tumor, $3 \mathrm{~cm}$ in diameter, with unclear margins (fig. 1a). Computed tomography (CT) revealed a low-density lesion with irregular margins and peripheral ring enhancement on delayed phase (fig. 1b). Under a diagnosis of poorly differentiated HCC in segment 6, the patient underwent liver resection. Macroscopically, the tumor in segment 6 appeared to be hard and whitish with hemorrhage and necrotic tissue (fig. 2a). The patient's postoperative course was uneventful. However, the tumor relapsed in the residual liver, lymph nodes and bone, and despite radiation therapy, the patient died 11 months after surgery.

Histological examination showed proliferation of spindle-shaped sarcomatoid carcinoma cells with unclear trabecular and pseudoglandular structures (fig. 2b). Moderately differentiated HCC with trabecular structure was observed, and transition from sarcomatoid HCC to typical HCC was present (fig. 2c). On immunohistochemical examination (fig. 3), carcinoma cells in sarcomatoid HCC were mostly positive for vimentin (DAKO, Glostrup, Denmark), partially positive for cytokeratin 7 (DAKO) and mostly negative but focally positive for hepatocyte (DAKO), whereas those of moderately differentiated HCC were positive for hepatocytes, but negative for cytokeratin 7 and vimentin. The non-tumor area showed micronodular cirrhosis with about $30 \%$ fatty metamorphosis in the lobules, scattered focal necrosis in the lobules and moderate inflammatory cellular infiltration in the portal area. 
Yoshida et al.: Hepatocellular Carcinoma with Sarcomatoid Change without Anticancer Therapies

\section{Discussion}

The pathogenesis of sarcomatoid HCC has not been fully clarified. Several researchers interpret sarcomatoid HCC as a combination of HCC and hepatic sarcoma [7, 8]. On the other hand, sarcomatoid components are thought to be derived from dedifferentiation or anaplasia in HCC, which was supported by the following histological findings: (1) the high incidence of vimentin expression in the spindle cell components, in which cytokeratin or alpha-fetoprotein was positive, (2) the presence of transitional features from ordinary HCC to spindle cell components, and (3) the very low incidence of primary sarcoma of the liver [1, 2]. Our case showed similar immunohistochemical findings for vimentin and cytokeratin and the presence of mutual shifting in sarcomatoid and typical HCC.

Sarcomatoid HCC shows characteristic CT findings. Due to the very poorly differentiated cells and their rapid growth, sarcomatoid HCC frequently exhibits central necrosis and hemorrhage as well as peripheral viable cancerous tissue with fibrous stroma. As a result, CT often shows an irregularly demarcated intrahepatic mass with delayed prolonged peripheral enhancement $[2,9]$. On the other hand, peripheral enhancement on CT images in the early phase is observed in other tumors, in which findings are different from sarcomatoid HCC [9]. In the present case, CT revealed a tumor with irregular margin and peripheral enhancement on delayed phase, thus suggesting poorly differentiated liver cancer.

When compared with typical HCC, the prognosis of sarcomatoid HCC was unfavorable due to widespread metastasis [1, 4, 9, 10]. Hwang et al. [11] reported that the 3-year survival rates for sarcomatoid HCC after liver resection and liver transplantation were 18.2 and $37.5 \%$, respectively. Furthermore, there were no significant differences between overall survival of patients with and without treatment [4]. Consistent with their report, our patient experienced relapse not only in the residual liver, but also the bone and lymph nodes 6 months after curative resection, and despite transarterial embolization and radiation therapy he died 5 months after recurrence.

The pathological diagnosis of sarcomatoid HCC is characterized by transitional features between sarcomatoid tumor and ordinary HCC, with a trabecular pattern observed in varying degrees $[1,3,4]$. In addition, the immunohistochemical study for cytokeratin, epithelial membrane antigen, hepatocyte and vimentin is helpful in the pathological diagnosis [6]. Generally, components of sarcomatoid lesions are positive for both cytokeratin (epithelial marker) and vimentin (mesenchymal marker) [1,2,10]. The tumor in the present case was diffusely positive for vimentin and cytokeratin 7 , and focally positive for hepatocytes, which is consistent with sarcomatoid HCC.

In summary, we herein report a case of sarcomatoid HCC without previous anticancer therapy. Sarcomatoid HCC has a worse prognosis and is likely to metastasize to both the residual liver and distant side organs. Even when a patient has not previously undergone anticancer therapies, we must consider sarcomatoid HCC when treating atypical HCC.

\section{Acknowledgements}

This work was supported by Grants-in-Aid for Scientific Research (A) 24249068 (T.T.) and (C) 23591972 (Y.M.) from the Ministry of Education, Culture, Sports, Science and Technology (MEXT), Japan. 
Yoshida et al.: Hepatocellular Carcinoma with Sarcomatoid Change without Anticancer Therapies

\section{Disclosure Statement}

The authors declare no conflicts of interest.

\section{References}

1 Maeda T, Adachi E, Kajiyama K, Takenaka K, Sugimachi K, Tsuneyoshi M: Spindle cell hepatocellular carcinoma. A clinicopathologic and immunohistochemical analysis of 15 cases. Cancer 1996;77:51-57.

2 Kakizoe S, Kojiro M, Nakashima T: Hepatocellular carcinoma with sarcomatous change. Clinicopathologic and immunohistochemical studies of 14 autopsy cases. Cancer 1987;59:310-316.

-3 Harataka J, Horie A: An immunohistochemical study of sarcomatoid liver carcinomas. Cancer 1991;68: 93-97.

4 Kojiro M, Sugihara S, Kakizoe S, Nakashima O, Kiyomatsu K: Hepatocellular carcinoma with sarcomatous change. A special reference to the relationship with anticancer therapy. Cancer Chemother Pharmacol 1989;23:4-8.

5 Komada N, Yamagata M, Komura K, Hayashi K, Maruyama T, Kataoka H, Koono M, Tsubouchi H: Hepatocellular carcinoma with sarcomatous change arising in primary biliary cirrhosis. J Gastroenterol 1997;32:95-101.

-6 Yokomizo J, Cho A, Yamamoto H, Nagata M, Takiguchi N, Kainuma O, Soda H, Mori M, Narumoto S, Asano T, Ryu M, Kondo F: Sarcomatous hepatocellular carcinoma without previous anticancer therapy. J Hepatobiliary Pancreat Surg 2007;14:324-327.

7 Shin P, Ohmi S, Sakurai M: Hepatocellular carcinoma combined with hepatic sarcoma. Acta Pathol Jpn 1981;31:815-824.

-8 Nagamine Y, Sasaki K, Kaku K, Takahashi M: Hepatic sarcoma associated with hepatoma. Acta Pathol Jpn 1978;28:645-651.

-9 Honda H, Hayashi T, Yoshida K, Takenaka K, Kaneko K, Fukuya T, Tateshi Y, Ro T, Maeda T, Masuda K: Hepatocellular carcinoma with sarcomatous change. Characteristic findings of two-phased incremental CT. Abdom Imaging 1996;21:37-40.

10 Eriguchi N, Aoyagi S, Okuda K, Hara M, Fukuda S, Tamae T, Ohdo M, Kanazawa N, Kawabata M, Kodama T: Unusual liver carcinomas with sarcomatous features. Analysis of four cases. Surg Today 2001;31:530-533.

11 Hwang S, Lee SG, Lee YJ, Ahn CS, Kim KH, Park KM, Moon KM, Moon DB, Ha TY, Yu ES, Choi GW: Prognostic impact of sarcomatous change of hepatocellular carcinoma in patients undergoing liver resection and liver transplantation. J Gastrointest Surg 2008;12:718-724.
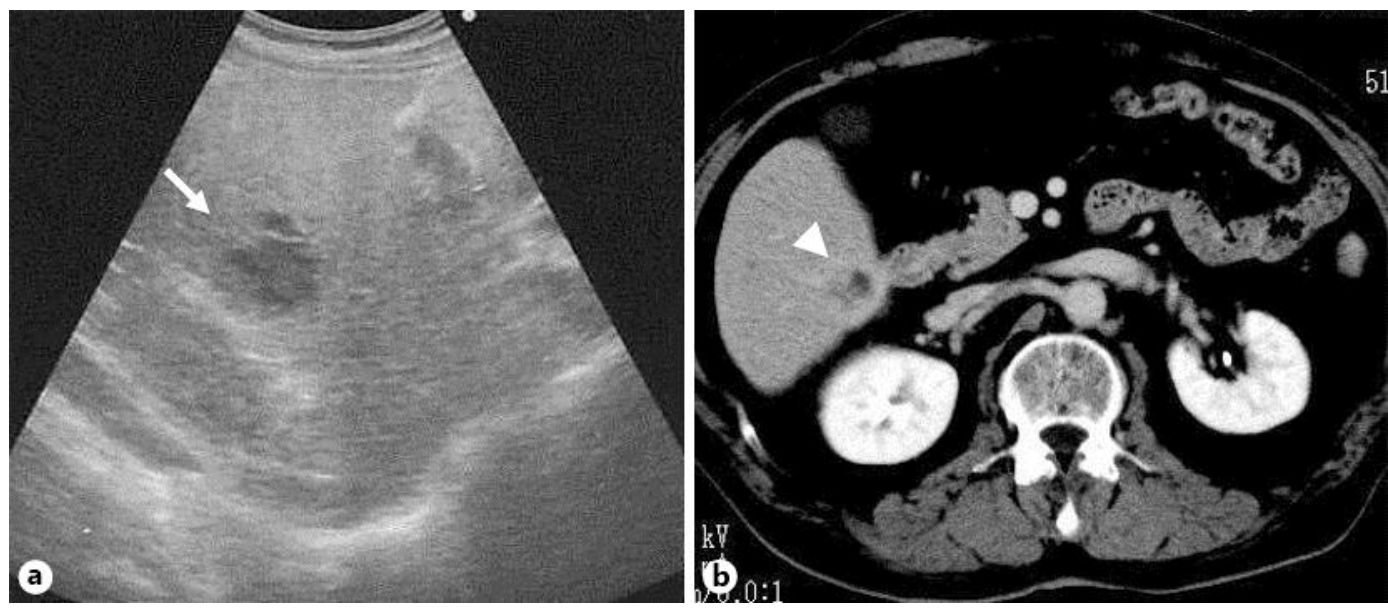

Fig. 1. Imaging modalities for the liver tumor in segment 6. a Ultrasonography showed a hypoechoic lesion with unclear margins that measured $30 \times 25 \mathrm{~mm}$ (arrow). b CT on delayed phase demonstrated peripheral enhancement of the tumor (arrowhead). 


\begin{tabular}{|c|c|c|}
\hline \multirow{3}{*}{$\begin{array}{r}\text { Case Reports in } \\
\text { Gastroenterology }\end{array}$} & \multirow{2}{*}{\multicolumn{2}{|c|}{ Case Rep Gastroenterol 2013;7:169-174 }} \\
\hline & & \\
\hline & DOI: $\underline{10.1159 / 000350558}$ & $\begin{array}{l}\text { (c) } 2013 \text { S. Karger AG, Basel } \\
\text { www.karger.com/crg }\end{array}$ \\
\hline
\end{tabular}
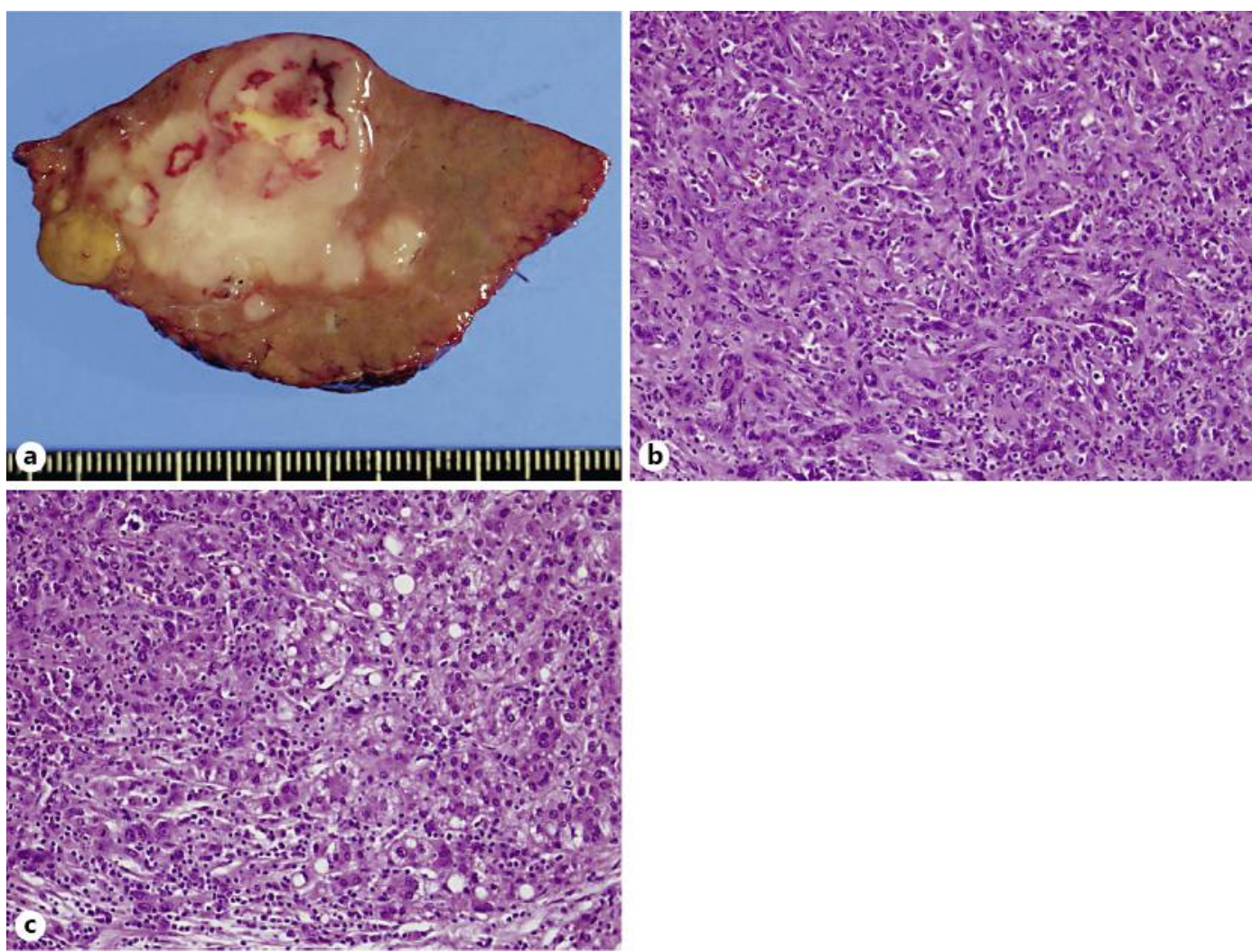

Fig. 2. Pathological findings of tumor in segment 6. a Macroscopically, the mainly whitish tumor with partial hemorrhage and necrosis included a small nodular lesion, slightly yellowish in color. b, c Histological findings showed proliferation of atypical spindle-shaped cells in the tumor, indicating sarcomatoid HCC (b), and a transition area between sarcomatoid pattern (upper right) and trabecular structure, indicating moderately differentiated HCC (lower left) (c). b, c Hematoxylin and eosin staining, $\times 200$. 


\begin{tabular}{|c|c|c|}
\hline \multirow{3}{*}{$\begin{array}{r}\text { Case Reports in } \\
\text { Gastroenterology }\end{array}$} & \multirow{2}{*}{\multicolumn{2}{|c|}{ Case Rep Gastroenterol 2013;7:169-174 }} \\
\hline & & \\
\hline & DOI: $\underline{10.1159 / 000350558}$ & $\begin{array}{l}\text { (c) } 2013 \text { S. Karger AG, Basel } \\
\text { www.karger.com/crg }\end{array}$ \\
\hline
\end{tabular}
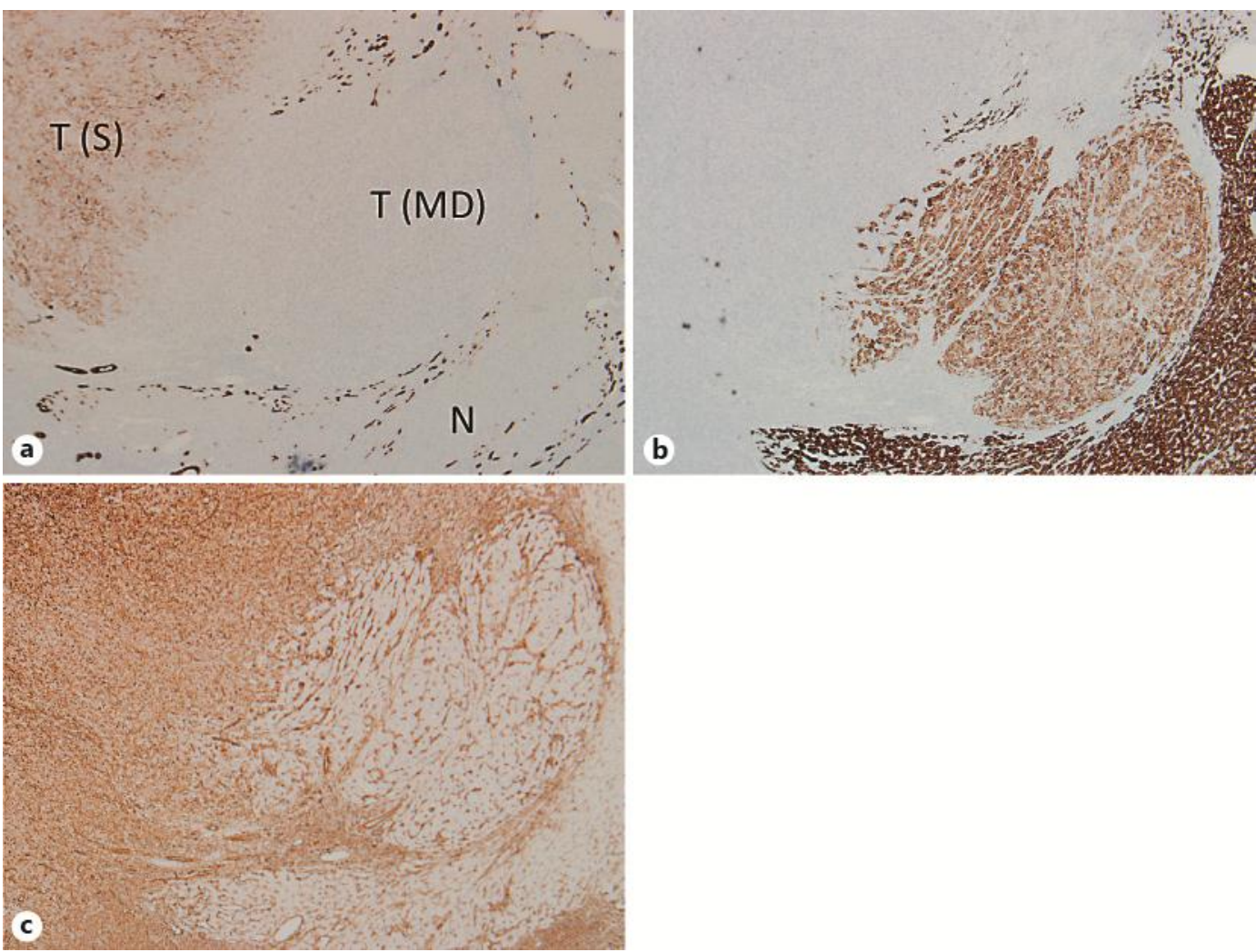

Fig. 3. Immunohistological examination of the tumor in segment 6. a Anti-CK7 antibody was positive in the sarcomatoid lesion and negative in moderately differentiated HCC and hepatocytes of the non-tumor area. In the non-tumor area, the bile ducts were positive. $\mathbf{b}$ Anti-hepatocyte antibody was negative in the sarcomatoid lesion but positive in HCC and hepatocytes in the non-tumor area. c Anti-vimentin was positive in the sarcomatoid lesion but was negative in moderately differentiated HCC and hepatocytes of the non-tumor area. a Hematoxylin and eosin staining. b, c Immunohistochemical staining, $\times 40$. $\mathrm{T}(\mathrm{S})=$ Sarcomatoid pattern of tumor; T (MD) = moderately differentiated HCC; N = non-tumor area. 